
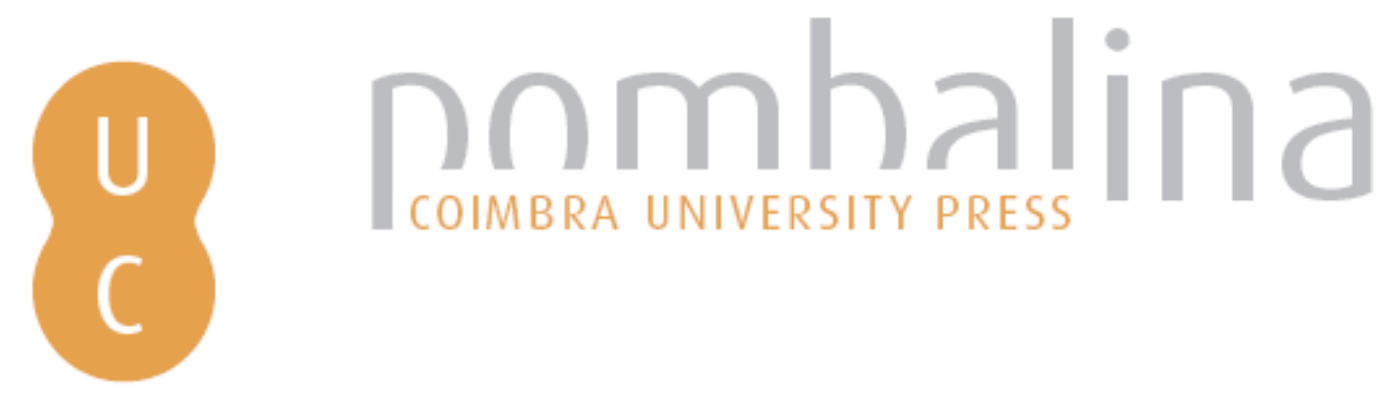

\title{
A atualidade de Alberti no diálogo contemporâneo entre a prática e a crítica
}

Autor(es): $\quad$ Monteiro, Giovana Helena de Miranda

Publicado por: Imprensa da Universidade de Coimbra

URL persistente:

URI:http://hdl.handle.net/10316.2/36670

DOI:

DOI:http://dx.doi.org/10.14195/978-989-26-1015-3_8

Accessed : $\quad$ 26-Apr-2023 09:54:44

A navegação consulta e descarregamento dos títulos inseridos nas Bibliotecas Digitais UC Digitalis, UC Pombalina e UC Impactum, pressupõem a aceitação plena e sem reservas dos Termos e Condições de Uso destas Bibliotecas Digitais, disponíveis em https://digitalis.uc.pt/pt-pt/termos.

Conforme exposto nos referidos Termos e Condições de Uso, o descarregamento de títulos de acesso restrito requer uma licença válida de autorização devendo o utilizador aceder ao(s) documento(s) a partir de um endereço de IP da instituição detentora da supramencionada licença.

Ao utilizador é apenas permitido o descarregamento para uso pessoal, pelo que o emprego do(s) título(s) descarregado(s) para outro fim, designadamente comercial, carece de autorização do respetivo autor ou editor da obra.

Na medida em que todas as obras da UC Digitalis se encontram protegidas pelo Código do Direito de Autor e Direitos Conexos e demais legislação aplicável, toda a cópia, parcial ou total, deste documento, nos casos em que é legalmente admitida, deverá conter ou fazer-se acompanhar por este aviso. 
IMPRENSA DA

UNIVERSIDADE

DE COIMBRA

COIMBRA

UNIVERSITY

PRESS

\section{NA GÉNESE DAS RACIONALIDADES MODERNAS II}

Em torno de Alberti e do Humanismo

MÁRIO KRÜGER et alii

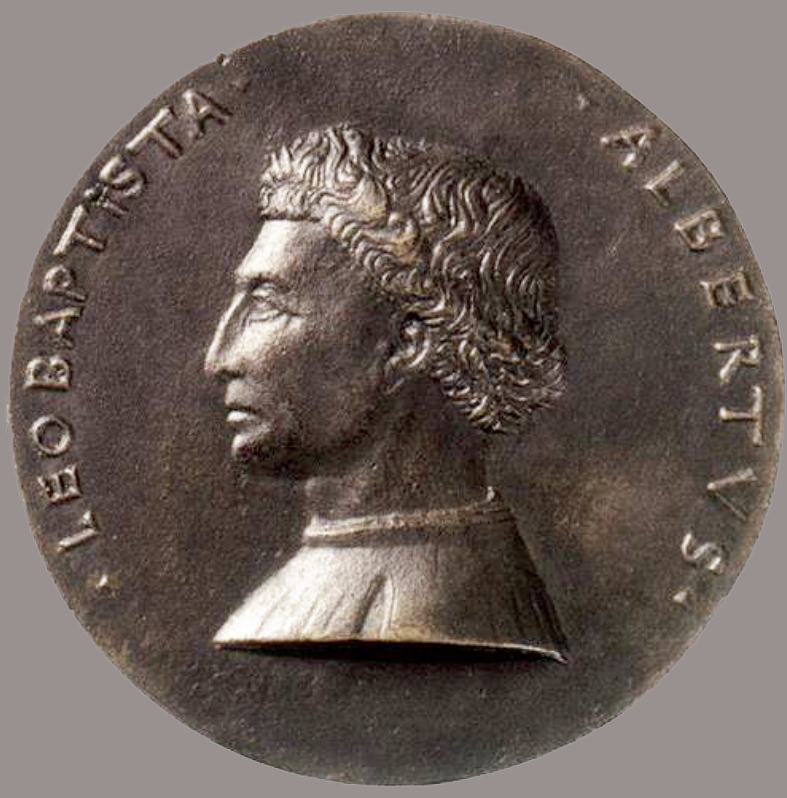




\section{A A TUALIDADE DE ALBERTI NO DIÁLOGO CONTEMPORÂNEO ENTRE A PRÁTICA E A CRÍTICA}

Giovana Helena de Miranda Monteiro

\section{Resumo}

O diálogo, instaurado por Alberti como um dos operadores metodológicos da arte edificatória, revela sua atualidade na participação dos habitantes e em seu envolvimento com a produção e a crítica do ambiente construído. Primordiais para Alberti, pensamento e ação em torno das relações das partes com o todo materializam-se no papel dos envolvidos na produção edificatória, em que o diálogo entre a prática e a crítica faz-se fundamento da construção de espaços que instituam sociedades. Apropriação; Vergesellshaftung (sociação); Entäusserung (alienação); Entfremdung (estranhamento); fetichização.

\section{Résumé}

Le dialogue, instauré par Alberti comme l'un des opérateurs de l'art édificatoire, est bénéfique pour la participation des habitants et leur engagement en faveur de la production et de la critique de l'environnement bâti. Primordiales selon Alberti, la pensée et l'action dans le cadre des liens entre les parties avec le tout sont matérialisées dans le rôle des acteurs de la production édificatoire, où le dialogue entre la pratique et la critique devient la fondation de la construction d'espaces qui instituent les sociétés.

Appropriation; Vergesellschaftung (sociation); Entäusserung (aliénation); Entfremdung (étrangeté); fétichisation. 


\begin{abstract}
The dialogue, established by Alberti as one of the methodological operators of the art of building, reveals its presence through the dwellers' participation and engagement with the production and criticism of the built environment. Essential to Alberti, thinking and action around the relations of the parts with the whole materialize in the role of whoever engages in the production of the built world, where the dialogue between practice and criticism presents itself as fundamental for the building of spaces where societies can flourish. Appropriation; Alienation; Estrangement; Fetichization.
\end{abstract}


A relação entre a atividade e seus efeitos ultrapassa o valor isolado de cada um deles. O resultado da atividade, o objeto produzido, é apenas um desses efeitos; o resumo, propriamente dito, da atividade de produção ${ }^{209}$. Se a importância do resultado prepondera sobre a da atividade, esse fenômeno pode ser investigado à luz do conceito de alienação. Uma análise etimológica do termo Entäusserung, utilizado por Marx ao referir-se à ideia de alienação, inclui entre seus significados o ato de "remeter para fora, extrusar, passar de um estado a outro qualitativamente distinto"210. Significa também "despojamento"; realização de uma ação de transferência em que se evidencia o sentido da exteriorização como momento de objetivação humana por meio de um produto resultante de sua criação. 211

"A exteriorização [Entäusserung] do trabalhador em seu produto tem o significado não somente de que seu trabalho torna-se um objeto, uma existência externa, mas, bem além disso, [que se torna uma existência] que existe fora dele, independente dele e estranha a ele." 212

A etimologia de Entäusserung evidencia o caráter ambivalente da alienação, que pode exteriorizar, através dos objetos produzidos, tanto o sentido quanto a carência de sentido vinculados à atividade de sua produção. "Sentido" é aqui abordado como instrumento de crítica, não um reservatório, princípio, origem ou finalidade, mas um efeito criador que ultrapassa as percepções e orienta criticamente a articulação entre pensamento e ação. ${ }^{213}$ Se ocorre da alienação ser levada a tornar-se exteriorização extremada, o laço entre atividade e

209 Cf. KARL MARX, Manuscritos econômico-filosóficos, São Paulo: Boitempo, 2010, p.82.

210 Cf. ibidem, p.16.

211 Cf. argumentos do tradutor Jesus Ranieri ao apresentar o termo usado por KARL MARX, Manuscritos econômico-filosóficos, São Paulo: Boitempo, 2010.

212 Cf. Ibidem, p.81.Grifos no original.

213 Cf. GILLES DELEUZE, Sobre Nietzsche e a imagem do pensamento[1968], In: A ilha deserta: e outros textos, São Paulo: Iluminuras, 2006, pp. 175-183. 
resultado tende a afrouxar-se, formando uma fenda em torno da qual pode brotar o estranhamento. "O estranhamento [Entfremdung] não se mostra somente no resultado, mas também, e principalmente, no ato da produção, dentro da própria atividade produtiva." 214 O estranhamento revela a percepção, nem sempre consciente, da incompletude e da incerteza. A percepção da presença de uma falta. A tendência a evitar esse desconforto torna a relação entre atividade e resultado susceptível de ser substituída, desviada, preterida 215 . O valor, tanto da atividade quanto do resultado, reside na composição entre forma, conteúdo e sentido 216 . A articulação desses elementos demanda um organismo em equilíbrio dinâmico, onde deixar-se cegar pela forma não é pior que reduzi-la a uma "mera" forma ${ }^{217}$. Os extremos dessa atitude reducionista podem converter a atividade em uma sequência de ações sem sentido e, o resultado, em um objeto sem valor. Não um valor que é veículo de "valores estabelecidos"218, mas um valor carregado de sentido crítico-criador, imbuído de uma razão arguta no exame de cada uma das partes e também do organismo que compõem em conjunto. Desviar-se desse valor remete à essência da fetichização: a transferência, para um objeto, de um complexo de sentido que deveria ser atributo de uma relação. O fetiche também desvia, para a materialidade de seu objeto, a energia que seria despendida na tarefa de lidar com a realidade. Seu mecanismo consiste em substituir a consciência pela ilusão, pelo devaneio, pois seu objeto dá corpo a uma espécie de desmentido do conhecimento; a relutância em assumir a realidade de uma situação. A tática do fetiche não é desprovida de virtude, e pode servir para adiar o confronto com a realidade até que

214 KARL MARX, op. cit, p.82.

215 Cf. SIGMUND FREUD, Além do princípio do prazer [1920], São Paulo: Companhia das Letras, 2010, pp. 161-239.

216 Cf. GEORGE SIMMEL, Georg Simmel: sociologia, Organização de Evaristo de Moraes Filho, São Paulo: Ática, 1983.

217 Cf. SLAVOJ ŽIŽEK, A visão em paralaxe, São Paulo: Boitempo, 2009.

218 Cf. GILLES DELEUZE, Sobre Nietzsche e a imagem do pensamento[1968], In: A ilha deserta: e outros textos, São Paulo: Iluminuras, 2006, pp.176-177. 
se esteja mais preparado para enfrentá-1a 219 . A transferência derivada desse desvio ou adiamento tem o intuito de amortizar o impacto que a consciência da incompletude e da incerteza têm sobre a decisão de enfrentar a realidade 220 . A consciência dessa falta estrutural tem o potencial de fortalecer o método segundo o qual serão empreendidas interpretações, intervenções, resignificações da realidade. Porém, cabe lembrar que onde há fetiche, há sintoma. Os sintomas trazem à luz o conhecimento que se tem mas com o qual ainda não se está disposto a lidar ${ }^{221}$. O sintoma, em sua própria forma, incorpora o conteúdo latente e se coloca a serviço de manifestar o que o fetiche pretende esconder. Com o intuito de escapar ao estranhamento, o fetiche extremiza a alienação. Muitas das relações estabelecidas com o ambiente construído inscrevem-se sob a égide dessa articulação e tornam-se perceptíveis através do próprio ambiente construído, cuja anatomia espelha as transformações de uma sociedade através do tempo. Mesmo sendo alvo de investimentos consideráveis, mudanças na configuração do espaço não necessariamente refletem ou instigam transformações nos sujeitos e nas sociedades. A mera mudança na forma não a institui como veículo de sentido. A identificação desses sintomas na edificatória contemporânea (Fig. 1), aponta para a repetição (Fig. 2), a sobreposição (Fig. 3), a discronia (Fig. 4 e 5).222

219 Cf. SLAVOJ ŽIŽEK, Em defesa das causas perdidas, São Paulo: Boitempo, 2011.

220 Cf. ibid, ARENDT, HANNAH, The human condition, Chicago: University of Chicago Press, 1998.

221 Cf. SLAVOJ ŽIŽEK, op. cit.

222 Cf. ALEXANDER MITSCHERLICH, Psychanalyse et urbanisme: réponse aux planificateurs, Paris: Éditions Gallimard, 1970; PIERRE CAYE, Moral et chaos: principes d'un agir sans fondement. Paris: Les éditions du Cerf, 2008, p.329; HENRI-PIERRE JEUDY, Espelho das cidades. Rio: Casa da Palavra, 2005. 


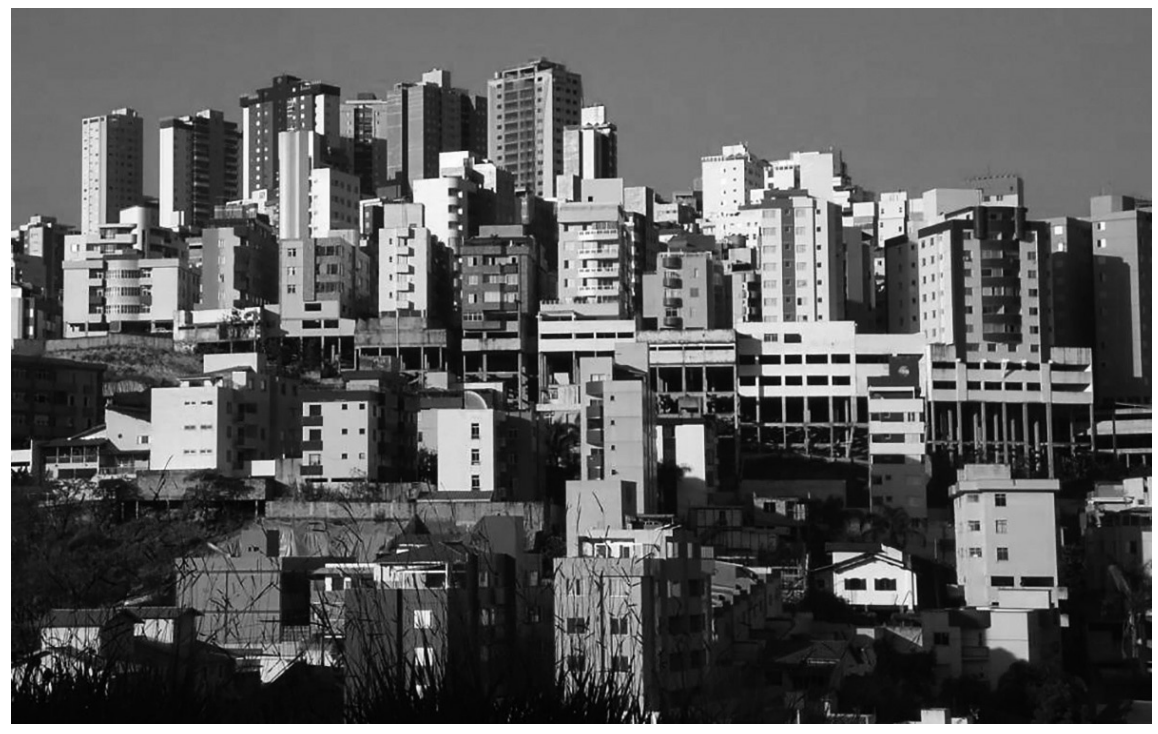

Fig. 1 - Panorama de Belo Horizonte a partir do bairro Estoril. Fonte: foto da autora, 2012.

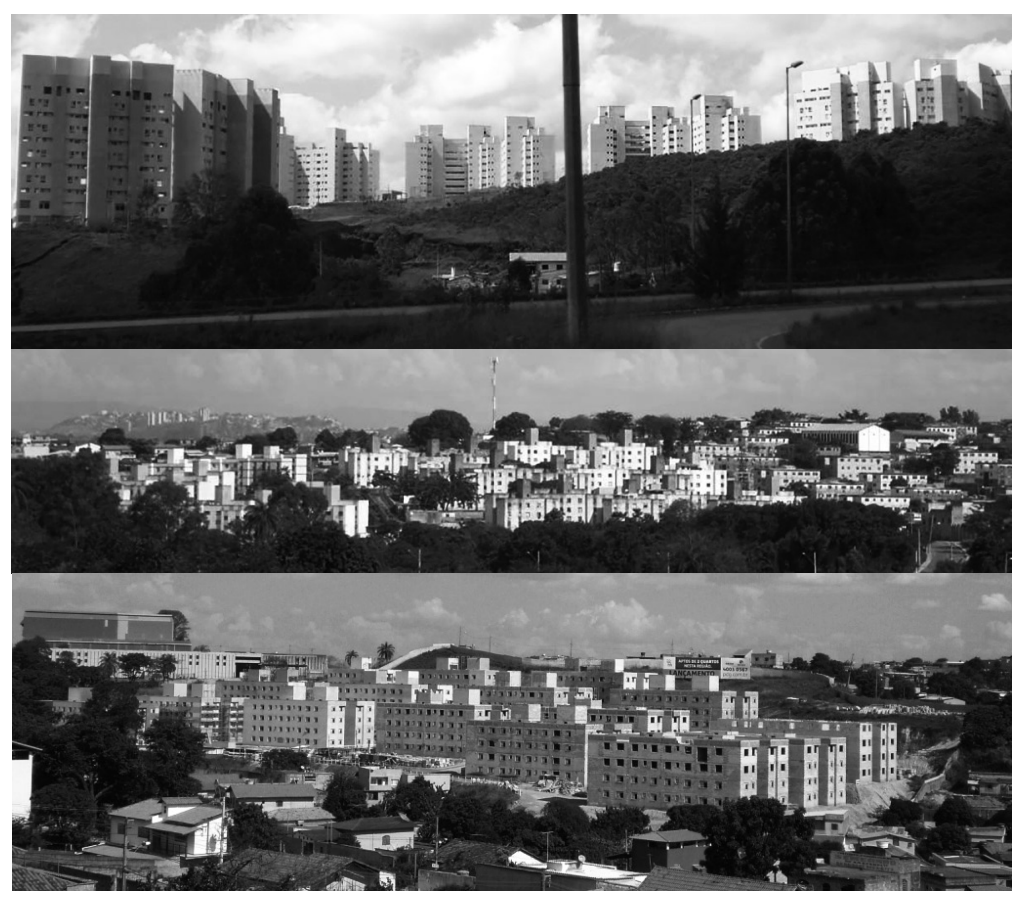

Fig. 2 - Cenas do ambiente construído, RMBH Fonte: fotos da autora, 2012. 


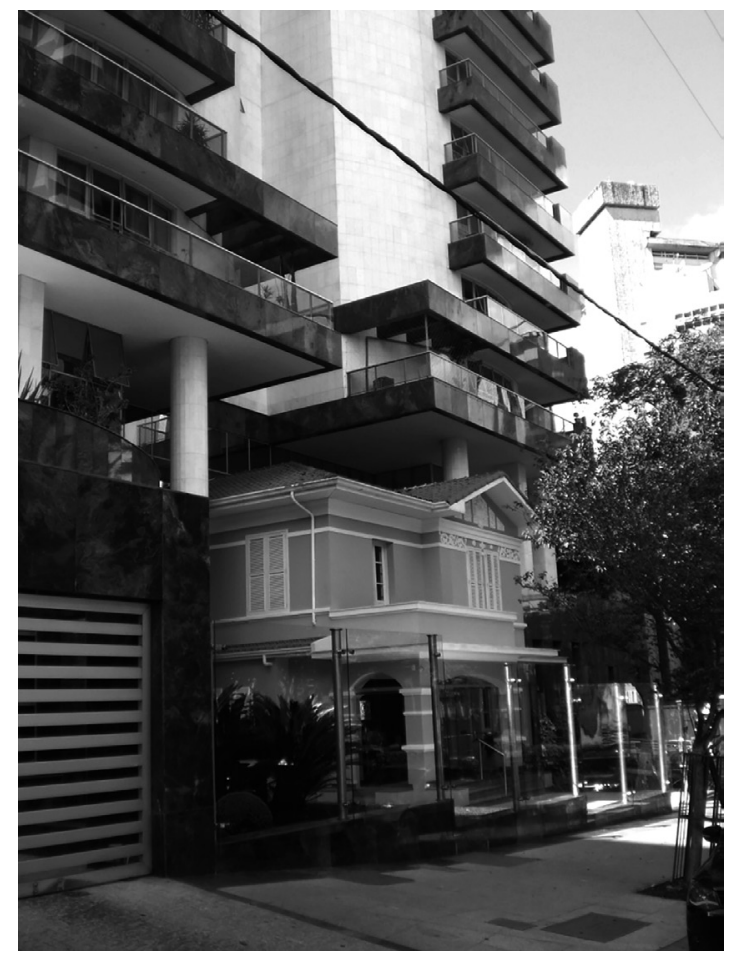

Fig. 3 - Rua Tomé de Souza, BH Fonte: foto da autora, 2012.

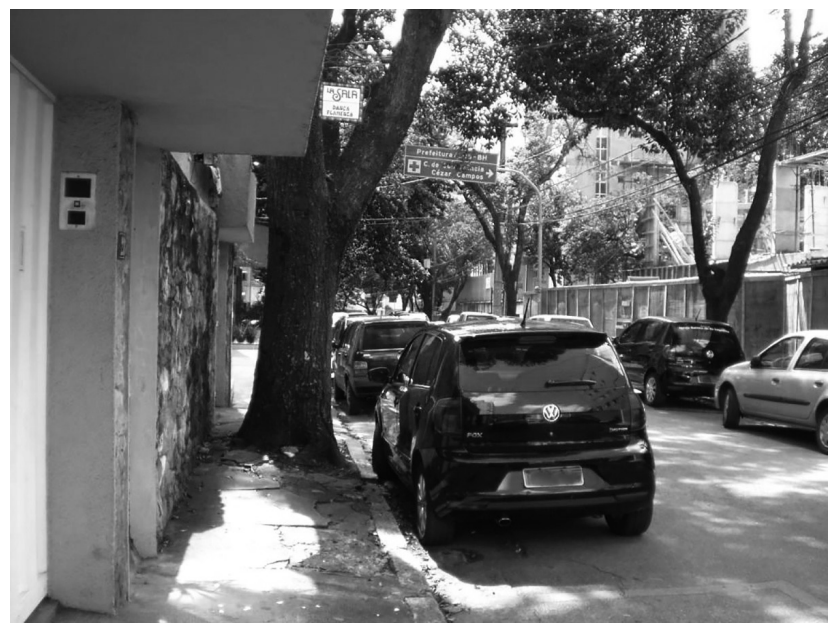

Fig. 4 - Rua Germano Torres

Entre ruas Maria Alves e Outono, Bairro Carmo, Belo Horizonte

Fonte: foto da autora, 2012. 


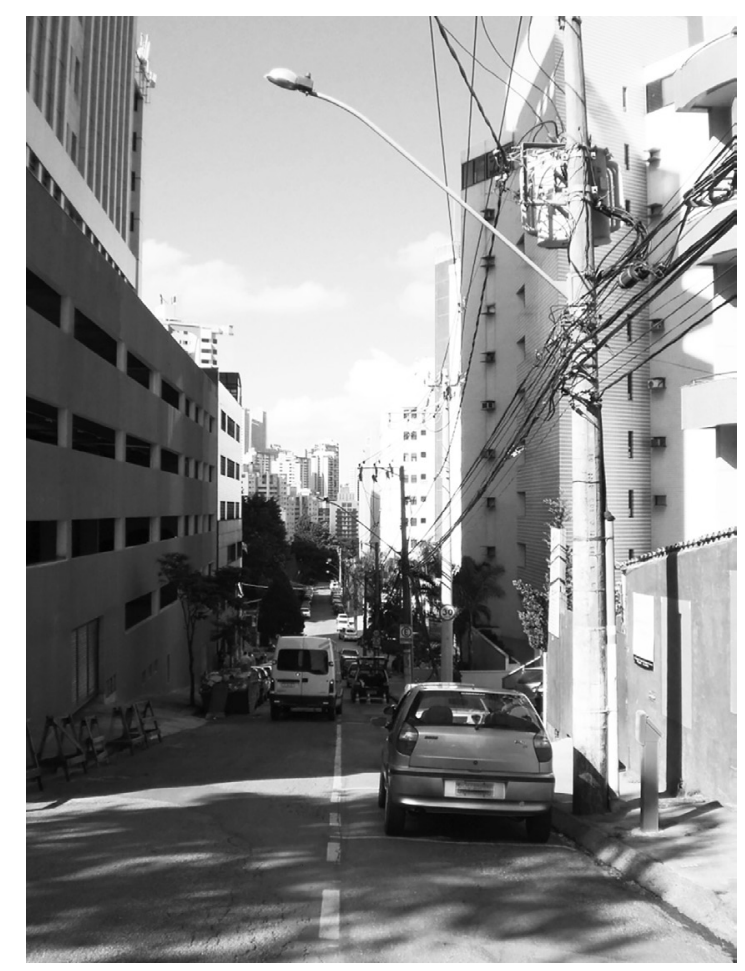

Fig. 5 - Bairro Vale do Sereno, Nova Lima, RMBH Fonte: foto da autora, 2012.

Enquanto a repetição e a sobreposição não exigem mais que as edificações para tornarem-se evidentes no ambiente construído, a discronia manifesta-se também na relação entre o parcelamento do solo e as edificações. Ruas abertas em atendimento a um determinado modo de vida, já demolido, são ocupadas por edifícios que carecem de outras sintaxes espaciais. Os efeitos da forma de articulação entre parcelamento do solo, implantação e escala das ruas e dos edifícios manifestam-se no conteúdo de sua fruição: a velocidade de passagem, o teor das relações humanas, o envolvimento consigo mesmo, com o outro e com o espaço em que se instituem. ${ }^{223}$

223 Uma elaboração mais extensa desse argumento encontra-se no capítulo 3 de GIOVANA HELENA DE MIRANDA MONTEIRO, O espaço público da rua como síntese das reflexões críticas do urbano: encontro das diferenças no contexto da diversidade sócio-espacial 
Se conduzida aos extremos da alienação e imbuída de estranhamento, a atividade de produção do ambiente construído não oferece resistência às forças indutoras de repetição. Efeito da redução da forma a uma mera forma, a repetição denota o desprezo pelo ciclo crítico que articula a atividade ao resultado ${ }^{24}$. Desse ciclo fazem parte os procedimentos que instauram a crítica no interior da prática projetual e também na fruição do edifício e da cidade. Alberti, no De re aedificatoria, aborda diversos desses procedimentos. Ao exercitar a crítica no desenrolar da prática, ele recomenda que o arquiteto conceda tempo ao apaziguamento de seu afã de construir e reexamine o projeto detalhadamente, julgando o conjunto com mais circunspecção. O que deve movê-lo não é o amor à invenção, mas os argumentos de sua razão ${ }^{225}$. Instaurando a prática no interior da crítica, Alberti entende que a fruição dos edifícios exige perspicácia e diligência do arquiteto, que deve examiná-los com o maior cuidado, estudando-lhes o ordenamento, o lugar, as características e dimensões das partes que os compõem. Sua inspeção visa identificar o que é raro, admirável e atribuído à engenhosidade do arquiteto que o elaborou. Alberti recomenda que, ao fruir a obra, procure-se apreender com arte e reflexão aquilo que se julgar poder ser melhor de outra forma, mesmo que não esteja mal-feito. ${ }^{226}$

$\mathrm{Na}$ articulação entre a prática e a crítica, nota-se a importância que Alberti confere à forma. Ele entende que, enquanto houver algo a ser aportado às suas competências e ao seu talento, o arquiteto não deve considerar-se satisfeito antes de tê-lo apreendido e assimilado, ou mesmo antes de ter conseguido, tanto quanto possível, dar-lhe aspeto e forma por meio dos objetos que produz. Fica claro, em Alberti, o quanto o

contemporânea na Região Metropolitana de Belo Horizonte, Dissertação de Mestrado, Belo Horizonte: Escola de Arquitetura da UFMG, 2012, Acedido em 08 de outubro de 2012, em: http://hdl.handle.net/1843/BUOS-8YQN5B.

224 Cf. Capítulo III de SIGMUND FREUD, O mal-estar na civilização, novas conferências introdutórias à psicanálise e outros textos. São Paulo: Companhia das Letras, 2010, pp. 45-60, e também das "Novas conferências introdutórias à psicanálise" em Ibidem, pp. 124-324.

225 Cf. LEON BATTISTA ALBERTI, L'art d'édifier. Paris: Seuil, 2004, pp.100-101 e pp. 142-143. Livro II, Capítulo 1 e Livro III, Capítulo 2.

226 Cf. Ibidem, p.460. Livro IX, Capítulo 10. 
processo de produção de um objeto é também resultado, exteriorização, da reedição de um conjunto de percepções e elaborações sobre o que foi anteriormente fruído, estudado, examinado. ${ }^{227}$ A composição de imaginação e conceção atribui valor ao trabalho do arquiteto quando reflete o engenho de seu gesto sobre a realidade: a escolha da forma e dos materiais, o discernimento em favor da composição, a conduta ao longo de sua realização. ${ }^{228}$ Alberti é severo quanto à negligência em quaisquer desses procedimentos, seja por falta de cuidado ou por indiferença. Segundo ele, tal postura compromete tanto a dignidade quanto o mérito da obra. "Deve-se consagrar muita atenção, cuidado e diligência ao estudo das partes que fazem da obra um organismo, e observar que mesmo as mais ínfimas podem ganhar forma pela inteligência e pela arte."229

Percebe-se a importância conferida à forma também no combate que ele institui contra a repetição. Para Alberti, os componentes de um organismo não devem firmar-se em um único e mesmo traçado. A supressão da diferença compromete a variedade, que é, em todas as coisas, "o sal da graça". Sua opinião é de que as obras passadas não podem trabalhar como restrições a novas proposições, mas como advertências instrutivas para a formação crítica do arquiteto. ${ }^{230} \mathrm{O}$ valor que Alberti confere à variedade não o exime de reconhecer a dificuldade de aliar comodidade, dignidade, beleza e refinada diversidade a cada uma das partes de uma composição. ${ }^{231}$ As atividades construtivas manifestam seu valor enquanto representação e instrumento do refinamento da conduta e da prática de uma razão própria à arquitetura. Os procedimentos elucidados por Alberti denotam que o arquiteto confere valor e sentido ao seu traba-

227 Cf. Aleph - Escola de Psicanálise, em 2012, sobre SIGMUND FREUD, Além do princípio do prazer [1920], em História de uma neurose infantil: ("O homem dos lobos"): além do princípio do prazer e outros textos (1917-1920). São Paulo: Companhia das Letras, 2010, pp. 161-239.

228 Cf. capítulos 8 a 10 do livro IX LEON BATTISTA ALBERTI, L'art d'édifier, Paris: Seuil, 2004, pp.452-462.

229 Cf. Livro I, Capítulo 9: Il faut donc consacrer beaucoup de soin et de diligence à l'étude des parties qui font de l'ouvrage un tout, et veiller à ce que même les plus infimes apparaissent conformées par l'intelligence et par l'art. ibidem, p.80.Tradução da autora.

230 Cf. ibidem, p.81. Livro I, Capítulo 9.

231 Cf. Ibidem, p.100. Livro II, Capítulo 1. 
lho na medida em que aprimora seu conhecimento e sua habilidade em fazer dialogarem atividade, resultado, prática e crítica. Essa articulação demanda delicadeza. A delicadeza parece ser um método contra o qual Alberti não se permite fazer concessões.

Os vínculos com que Alberti articula esses elementos incluem forma, conteúdo e sentido. Seus princípios e axiomas oferecem-se como ferramentas de combate à alienação extremada na produção edificatória, principalmente quando recomenda ao arquiteto dedicar-se com discernimento técnico e crítico à atividade que tem diante de si. Quando instaura o papel enobrecedor do uso e o articula à necessidade, à comodidade e ao $\operatorname{prazer}^{232}$, Alberti confere sentido à fruição crítica do ambiente construído. A contribuição de cada sujeito a esses procedimentos alimenta o sentido da arquitetura, seu valor como veículo e espelho da transformação da sociedade. Esse valor da edificatória elucida a essência do combate ao fetiche em Alberti que, atento aos condicionantes da realidade, não se furta aos seus tensionamentos e contradições ${ }^{233}$. Recomendando sagacidade contra a pressão do desejo de edificar, Alberti alerta para essa pulsão, cuja força pode levar o arquiteto a pular etapas, substituir diligência por imediatismo, repetir sem refletir, inovar sem ponderar. Condenando os excessos, Alberti posiciona-se contra o desperdício e a ausência de limites por considerá-los insuficientemente compensatórios às questões do edificar.

Contudo, as recomendações de Alberti frequentemente escapam às práticas contemporâneas. O crítico de arquitetura Hal Foster é categórico ao afirmar: "Projetar um espaço público não é, ipso fato, trabalhar para o bem público, e oferecer um edifício icônico não é, ipso fato, exercer um papel cívico." 234 Sua crítica, no que tange ao quesito fruição dos

232 Cf. LEON BATTISTA ALBERTI, L'art d'édifier. Paris: Seuil, 2004, p.80. Livro I, Capítulo 9: (...) toute l'essence de l'édification découle de la nécessité; la commodité l'a nourrie et l'usage l'a anobile; enfin on en vint à songer au plaisir, bien que le plaisir lui-même ait toujours eu en horreur les excès de tout genre.

233 Cf. NELLA BIANCHI BENSIMON, Unicité du regard et pluralité des voix: essai de lecture de Leon Battista Alberti. Paris: Presses de La Sorbonne Nouvelle, 1998, p.19.

234 "To design a public space is not, ipso fato, to work for the public good, and to offer an iconic building is not, ipso fato, to play a civic role." HAL FOSTER, The art-architecture complex. New York: Verso, 2011, p.33. Tradução da autora. 
lugares e edifícios, confronta a "experiência" que, segundo ele, muitos arquitetos querem oferecer através de suas obras. Tais edifícios visam afetar as pessoas através da miscelânia de real com virtual, ou mesmo através de sentimentos alheios e impostos ao fruidor que, apesar de tudo, não se transforma a partir dessa "experiência". Por mais que aprimorem seus efeitos especiais, essas tentativas não conseguem envolver o espectador como fruidor ativo. O edifício parece tentar substituí-lo, realizando em seu lugar a atividade de percepção. "Essa é uma nova versão do velho problema da fetichização, posto que se apodera de nossos pensamentos e sensações, processa-os como imagens e efeitos, e as devolve para que, pasmos, mostremo-nos gratos."235

Nessa dinâmica, os efeitos que seriam produzidos ao longo da fruição, e em decorrência dela, são substituídos por outros, heteronomamente replicados. A crítica de Foster, na contramão dessas tendências contemporâneas, defende a mobilidade e o intercâmbio de estímulos, percepções e ideias que, em cada sujeito, podem instigar a consciência e a intenção de transformar a realidade. ${ }^{236}$ Porém, percepção e intenção, apenas, não são suficientes. A percepção está muito próxima das coisas e a intenção, muito próxima das sensações e impressões causadas pelas coisas. À subjetividade atordoada e socialmente inerte que a espetacularização incentiva deve-se opor algum tipo de articulação. A proposta de Alberti é fazê-la através do diálogo ${ }^{237}$. Em Alberti, o sentido da edificatória vai além de simplesmente oferecer respostas e interpretações ${ }^{238}$, pois seu processo de produção torna-a capaz de aportar algo às demandas

235 "In this way the phenomenological reflexivity of "seing oneself see" approaches its opposite: a space (an installation, a building) that seems to do the perceiving for us. This is a new version of the old problem of fetichization, for it takes our thoughts and sensations, processes them as images and effects, and delivers them back to us for our appreciative amazement." HAL FOSTER, op. cit, p.12.

236 Cf. SIGMUND FREUD, O inconsciente [1915]. In: Introdução ao narcisismo, ensaios de metapsicologia e outros textos (1914-1916). São Paulo: Companhia das Letras, 2010, p. 127.

237 Cf. NELLA BIANCHI BENSIMON, op. cit, p.20.

238 Freud aborda a importância de não interpretar o desejo nem traduzir um sintoma em FREUD, Sigmund. Recomendações ao médico que pratica a psicanálise [1912]. São Paulo: Companhia das Letras, 2010, pp. 147-162. 
latentes e manifestas dos sujeitos e das coletividades ${ }^{239}$. Esse processo busca o equilíbrio dinâmico sem negar a instabilidade e a impermanência que lhe são inerentes.

Adotar o adjetivo "atual" para fazer referência a Alberti, demanda salientar a ambiguidade desse termo, que designa tanto o que está em ato quanto o que caracteriza a época corrente. Constrói-se o valor no trabalho sobre a interpretação do que esses sentidos compõem em conjunto e na postura ativa de estabelecer com eles uma relação no presente ${ }^{240}$. As reflexões sobre a atualidade de Alberti estabelecem-se no trabalho sobre a interpretação do valor que ele atribui ao diálogo enquanto princípio metodológico ${ }^{241}$ provedor de uma articulação, em ato, entre a prática e a crítica.

O diálogo promove articulações no interior de cada um dos processos de prática e de crítica. No interior da crítica, o diálogo possibilita a elaboração de conceitos formulados ao longo da observação e da experimentação da realidade. ${ }^{242} \mathrm{O}$ trabalho sobre a interpretação da realidade autoriza o uso desses conceitos na prática, onde a lógica de sua formulação abre-se à reedição proporcionada pelo diálogo, que faz ver aspetos da realidade inapreensíveis apenas pela percepção ${ }^{243}$. Ao abordar conceitualmente os objetos ao longo da atividade de produzi-los, resguarda-se seu sentido. O diálogo, enquanto ferramenta no processamento dessas percepções, elucida o caráter provisório tanto das questões quanto das tentativas de respondê-las. O diálogo confere mobilidade às ideias, que podem ser

239 Cf. JORGE MÁRIO JÁUREgUi, Luz e Metáfora: Um Olhar Sobre o Espaço e Significado. In: Congresso Internacional de Psicanálise e Interseções-Arquitetura, I., 2002. Porto Alegre: 2002. Acedido em 01 de setembro de 2012, em: http://www.jauregui.arq. br/psicanalise.html.

240 Cf. FRANCESCO FURLAN, "o valor está na relação", Texto e Imagem III - Verba e Picturae em Alberti, em Na Gênese das Racionalidades Modernas: Em Torno de Alberti, 1, 2011. Belo Horizonte: Escola de Arquitetura da UFMG, 2011. Acedido em 24 de março de 2012, em: http://www.ufmg.br/ieat/2012/01/na-genese-das-racionalidades-modernas-em-torno-de-alberti/.

241 Segundo a categorização de Françoise Choay na Introdução da edição de LEON BATTISTA ALBERTI, L'art d'édifier. Paris: Seuil, 2004.

242 Cf. EVANDRO MIRRA, O conceito, os fundamentos, a ciência. In: Traçados da Pulsão. Belo Horizonte: Aleph Escola de Psicanálise, [2012] 2014, pp. 21-26.

243 Cf. ibid e SIGMUND FREUD, O inconsciente [1915]. In: Introdução ao narcisismo, ensaios de metapsicologia e outros textos (1914-1916). São Paulo: Companhia das Letras, 2010, pp. 99-150. 
resignificadas e transformadas ao longo ou como efeito da transmissão, estendendo sua duração, aprofundando seu sentido, intensificando seu valor e potencializando seus efeitos.

Instrumento de resistência contra a fetichização e o estranhamento, o método albertiano abriga a convivência com a incerteza e com a instabilidade, aproximando-se de torná-las suportáveis. Em Alberti e Paul Valéry a crítica é tanto causa quanto efeito do trabalho sobre a interpretação da realidade, que deve fazer prova à comodidade, à utilidade e à agradabilidade produzidas por sua conjunção. ${ }^{244}$ Segundo Valéry, o prazer despertado por um edifício remete ao ato de deslocá-lo através do pensamento crítico, variando e fruindo um grande número de combinações possíveis, até torná-lo potencialmente outro. ${ }^{245}$

Essas reflexões acerca da atualidade de Alberti fazem-se representar pela obra de um arquiteto contemporâneo que, nascido na Argentina, exerce, a partir do Brasil, há mais de trinta anos, uma abordagem transformadora dos espaços e da realidade. Do conjunto da obra de Jorge Mário Jáuregui, identificam-se produtos ${ }^{246}$ que remetem a operadores e axiomas do De re aedificatoria. Observa-se que o pensamento albertiano permeia tanto as reflexões teóricas quanto o trabalho prático de Jáuregui. Sua abordagem crítica evidencia a prática de valorização dos espaços públicos urbanos em áreas onde a realidade apresenta elevado grau de complexidade sócio-espacial, da qual o Brasil é exemplo profícuo. A carência de espaços públicos, no Brasil, estende-se também a regiões onde predominam famílias de poder aquisitivo mais elevado, paradoxo que encontra máxima expressão na ambiência das favelas e dos condomínios fechados. A exigüidade ou mesmo inexistência de espaços públicos em

244 Cf. PIERRE CAYE, Moral et chaos: principes d'un agir sans fondement. Paris: Les éditions du Cerf, 2008, p. 110 e LEON BATTISTA ALBERTI, L'art d'édifier. Paris: Seuil, 2004, p.80. Livro I, Capítulo 9: (...) toute l'essence de l'édification découle de la nécessité; la commodité l'a nourrie et l'usage l'a anobile; enfin on en vint à songer au plaisir, bien que le plaisir lui-même ait toujours eu en horreur les excès de tout genre. Tradução da autora.

245 "(...) a imobilidade do edifício é exceção; o prazer é deslocar-se até movê-lo e fruir todas as combinações oferecidas por seus membros, que variam." PAUL VALÉRY, Introdução ao método de Leonardo da Vinci. São Paulo: Editora 34, 1998, p.85.

246 Imagens disponíveis no site do arquiteto www.jauregui.arq.br 
ambos denota a desnutrição cívica de que a anatomia de muitas cidades brasileiras tem sido, progressivamente, espelho. Nas áreas abordadas por Jáuregui, menor escala não significa necessariamente menor complexidade. Isso, no entanto, não limita a capacidade ordenadora de um aporte metodológico que parte da leitura e consideração do pré-existente para elaborar intervenções sobre a realidade. Essas intervenções articulam-se à percepção e organização de quem se interessa e se envolve no processo de transformá-la. O diálogo instituído nos processos de fruir e produzir transforma-os respectivamente em crítica e prática. Esse método dialógico articula teoria e experiência sem eliminar as incertezas ou controvérsias próprias dos organismos a que ele se aplica. O diálogo, em Jáuregui, reedita o método albertiano, não sem ampliá-lo. Uma dinâmica que expõe o organismo à instabilidade, mas essa fragilidade é compensada pelo gesto coletivo que a constitui ${ }^{247}$. Em concinnitas com Alberti, Jáuregui entende que a realidade compõe-se de múltiplas relações humanas, cujo sentido é inseparável de sua articulação entre si e com o espaço em que se inserem. ${ }^{248}$

A exemplo de Alberti, Jáuregui reconhece o papel do desejo e da singularidade dos sujeitos na articulação com o espaço. Nesse sentido, Jáuregui elucida a importância que os habitantes desses complexos organismos urbanos conferem à beleza do ambiente construído, reivindicando-a em demandas manifestas. A beleza de que sentem falta, afirma Jáuregui, não remete apenas à aparência dos edifícios e à harmonia de sua disposição em composição com o lugar. O sentido primordial dessa beleza parte de sua capacidade de criar e manter afetos, provocando o interesse da comunidade pelo desenrolamento dos sujeitos e das coletividades no espaço em que se instituem. Esse espaço simboliza e reflete a consciência de sua capacidade de transformação. Independentemente do grau de complexidade da realidade local, em qualquer tempo e lugar onde o humano e a virtù representem algum valor durável, os desafios da edificatória parecem demandar que se transforme em ato a atualidade de Alberti.

\footnotetext{
247 Cf. EVANDRO MIRRA, op. cit, pp. 21-26.

248 Cf. NELLA BIANCHI BENSIMON, op. cit, p.14.
} 